\title{
Faktor Koreksi Nilai Laju Endap Darah (LED) Pada Penderita Tuberkulosis Menggunakan Metode Westergren dan Wintrobe
}

\author{
Rizki Amalia Dewi Sartika, Siti Zaetun, Yudha Anggit Jiwantoro \\ Jurusan Analis Kesehatan, Poltekkes Kemenkes Mataram, Indonesia
}

\begin{tabular}{l}
\hline Article Info \\
\hline Article history: \\
Received Sep $12^{\text {th }}, 2020$ \\
Revised Feb $02^{\text {nd }}, 2021$ \\
Accepted Mar $09^{\text {th }}, 2021$ \\
\hline
\end{tabular}

\section{Keyword:}

Correction factor,

ESR,

Tuberculosis Sufferers,

Westergren,

Wintrobe,

\begin{abstract}
The LED test is a test that measures the deposition rate of erythrocytes and describes the composition of the plasma and the ratio between erythrocytes and plasma. An increase in the ESR value compared to previous examinations indicates an infectious / inflammatory process. LED inspection methods include the Westergren and Wintrobe methods, both of these methods are manual methods. The research objective in this study was to determine the correction factor for the value of the sedimentation rate in tuberculosis patients using the Westergren and Wintrobe methods. The research method used in this study was pre-experimental with 2 groups of LED treatments, namely tested by the Westergren and Wintrobe methods. The results showed that the number of LED examination results of the westergren method was $622 \mathrm{~mm} /$ hour with a mean of $38.875 \mathrm{~mm} / \mathrm{hour}$ and the number of LED examination results with the wintrobe method was $520 \mathrm{~mm} /$ hour with an average of $32.5 \mathrm{~mm} /$ hour. The westergren method's value range is $12-115 \mathrm{~mm} /$ hour, the wintrobe method's value range is $18-47 \mathrm{~mm} /$ hour then the LED examination results from the westergren and wintrobe methods are multiplied by the correction factor then the multiplication results will be included in the value range of each method, the method that results the calculations are more within the value range is the better method for performing LED checks. The results of the Mann Whitney analysis showed a p value of $0.895>0.05$. Because the $p$ value is greater than $\alpha 0.05$, it can be concluded that there is no significant difference between the two groups and thus Ha is rejected. The conclusion of this study is that the westergren method is the best method to use for conducting LED checks than the wintrobe method because the results of the westergren method examination which have been multiplied by the correction factor are more in the value range, namely 15 multiplication results $(93.75 \%)$.
\end{abstract}

\begin{abstract}
ABSTRAK
Tes LED ialah tes yang mengukur kecepatan pengendapan eritrosit dan menggambarkan komposisi plasma serta perbandingannya antara eritrosit dan plasma. Peningkatan nilai LED dibandingkan pemeriksaan sebelumnya menunjukkan adanya suatu proses infeksi/inflamasi. Metode pemeriksaan LED diantaranya metode westergren dan wintrobe, kedua metode ini merupakan cara manual. Tujuan penelitian pada penelitian ini untuk mengetahui faktor koreksi nilai laju endap darah pada penderita tuberkulosis menggunakan metode westergren dan wintrobe. Metode penelitian yang digunakan pada penelitian ini bersifat pre-eksperimen dengan 2 kelompok perlakuan LED yaitu diuji dengan metode westergren dan wintrobe. Hasil penelitian didapatkan jumlah hasil pemeriksaan LED metode westergren $622 \mathrm{~mm} / \mathrm{jam}$ dengan rerata 38,875 mm/jam dan jumlah hasil pemeriksaan LED metode wintrobe $520 \mathrm{~mm} / \mathrm{jam}$ dengan rerata 32,5 mm/jam. Rentang nilai metode westergren $12-115 \mathrm{~mm} / \mathrm{jam}$, rentang nilai metode wintrobe $18-47 \mathrm{~mm} / \mathrm{jam}$ kemudian hasil pemeriksaan LED dari metode westergren dan wintrobe dikalikan dengan faktor koreksi kemudian hasil perkalian akan dimasukkan dalam rentang nilai masing-masing metode, metode yang hasil perhitungannya lebih banyak berada dalam rentang nilai adalah metode yang lebih baik untuk melakukan pemeriksaan LED.
\end{abstract}


Hasil analisis Mann Whitney menunjukkan nilai p 0,895>0,05. Karena nilai p lebih besar dari $\alpha 0,05$ maka dapat disimpulkan bahwa tidak terdapat perbedaan yang bermakna antara dua kelompok dengan begitu Ha ditolak. Kesimpulan dari penelitian ini metode westergren adalah metode yang paling baik digunakan untuk melakukan pemeriksaan LED dari pada metode wintrobe karena hasil pemeriksaan metode westergren yang telah dikalikan dengan faktor koreksi lebih banyak berada dalam rentang nilai yaitu 15 hasil perkalian $(93,75 \%)$.

Kata Kunci : Faktor koreksi, LED, penderita tuberkulosis, westergren, wintrobe

\section{Pendahuluan}

Tes laju endap darah ialah tes yang mengukur kecepatan pengendapan eritrosit dan menggambarkan komposisi plasma serta perbandingannya antara eritrosit dan plasma (Dekayana, 2019). Nilai LED yang lebih tinggi dari normal mengindikasikan adanya suatu lesi yang aktif, peningkatan nilai LED dibandingkan pemeriksaan sebelumnya menunjukkan adanya suatu proses infeksi/inflamasi yang meluas, sedangkan nilai LED yang kurang dari normal dibandingkan sebelumnya menandakan adanya suatu perbaikan (Cha et al., 2009). Pemeriksaan LED bermanfaat untuk memantau perjalanan penyakit dan memantau keberhasilan terapi penyakit kronik misalnya arthritis reumatoid dan tuberkulosis (Dekayana, 2019).

Tuberkulosis adalah penyebab utama kesembilan kematian di seluruh dunia dan penyebab utama dari satu agen infeksius, peringkat di atas HIV / AIDS. Pada tahun 2016, diperkirakan ada sekitar 1,3 juta TB kematian di antara orang HIV-negatif (turun dari 1,7 juta di 2000) dan tambahan 374.000 kematian di antara orang HIV-positif orang Pakistan (Global Tuberculosis Report, 2017). Ada beberapa metode pemeriksaan LED diantaranya metode westergren dan wintrobe, kedua metode ini merupakan cara manual. Setiap metode tersebut memiliki nilai rujukan, kelebihan dan kekurangan tersendiri. Kelebihan dan kekurangan tersebut sangat mempengaruhi validitas hasil pemeriksaan LED. Metode westergren merupakan metode yang disarankan oleh International Communitte for Standarization in Hematology (ICSH) (Liswanti, 2014). Berdasarkan masalah diatas peneliti ingin mengetahui mana teknik pemeriksaan yang akurat dan lebih baik agar dapat dijadikan gold standart pemeriksaan LED.

\section{Metode Penelitian}

Rancangan penelitian yang digunakan adalah bersifat pre-eksperiment dengan jumlah sampel sebanyak 32 pasien tuberkulosis dan 4 orang sebagai control darah normal. Teknik sampling yang digunakan berupa non random purposive sampling(Jiwantoro \& Jannah, 2019). Penelitian dilakukan di Laboratorium UPT. BLUD Puskesmas Lingsar pada bulan Februari 2020. Analisa data hasil penelitian menggunakan Independent $T$ Test dengan alpha 0,05.

\section{Hasil Penelitian dan Pembahasan}

Hasil pengukuran nilai laju endap darah pada sampel darah penderita tuberkulosis yang ditambahkan antikoagulan EDTA dan natrium sitrat 3,8\% dengan metode westergren dapat dilihat pada tabel 1.

Tabel 1 Nilai hasil pemeriksaan LED penderita tuberkulosis dengan metode wetergren

\begin{tabular}{|c|c|c|c|c|}
\hline No. & Nama & Usia & Hasil Pemeriksaan LED & Derajat BTA \\
\hline 1 & Ny "M" & 45 tahun & $43 \mathrm{~mm} / \mathrm{jam}$ & +1 \\
\hline 2 & Ny "M" & 66 tahun & $22 \mathrm{~mm} / \mathrm{jam}$ & +1 \\
\hline 3 & Tn "S" & 43 tahun & $48 \mathrm{~mm} / \mathrm{jam}$ & +1 \\
\hline 4 & Tn "M" & 50 tahun & $12 \mathrm{~mm} / \mathrm{jam}$ & +2 \\
\hline 5 & Ny "M" & 39 tahun & $115 \mathrm{~mm} / \mathrm{jam}$ & +2 \\
\hline 6 & Tn "H" & 60 tahun & $22 \mathrm{~mm} / \mathrm{jam}$ & +1 \\
\hline 7 & Ny "A" & 61 tahun & $18 \mathrm{~mm} / \mathrm{jam}$ & +1 \\
\hline 8 & Ny "M" & 49 tahun & $42 \mathrm{jam} / \mathrm{jam}$ & +1 \\
\hline 9 & Ny "W" & 53 tahun & $37 \mathrm{~mm} / \mathrm{jam}$ & +1 \\
\hline 10 & Tn "M" & 57 tahun & $16 \mathrm{~mm} / \mathrm{jam}$ & +1 \\
\hline 11 & Ny "D" & 33 tahun & $20 \mathrm{~mm} / \mathrm{jam}$ & +1 \\
\hline 12 & Ny "S" & 66 tahun & $78 \mathrm{~mm} / \mathrm{jam}$ & +1 \\
\hline
\end{tabular}




\begin{tabular}{|c|c|c|c|c|}
\hline No. & Nama & Usia & Hasil Pemeriksaan LED & Derajat BTA \\
\hline 13 & Ny "M" & 42 tahun & $24 \mathrm{~mm} / \mathrm{jam}$ & +1 \\
\hline 14 & Ny "A" & 50 tahun & $66 \mathrm{~mm} / \mathrm{jam}$ & +2 \\
\hline 15 & Ny "M" & 39 tahun & $27 \mathrm{~mm} / \mathrm{jam}$ & +1 \\
\hline 16 & Ny "S" & 50 tahun & $32 \mathrm{~mm} / \mathrm{jam}$ & +3 \\
\hline \multicolumn{3}{|c|}{ Jumlah } & $622 \mathrm{~mm} / \mathrm{jam}$ & \\
\hline \multicolumn{6}{|c|}{ Rerata } & $38,875 \mathrm{~mm} / \mathrm{jam}$ & \\
\hline
\end{tabular}

Pada tabel 1 menunjukkan bahwa sebagian besar yaitu $75 \%$ orang termasuk dalam kategori positif 1 , $18,75 \%$ orang kategori positif 2 , dan $6,25 \%$ orang kategori positif 3 . Hal ini dapat disimpulkan bahwa sebagian besar penderita tuberkulosis paru termasuk dalam kategori derajat BTA positif 1 yaitu ditemukan 10-99 dalam 100 lapang pandang. Tingkat kepositifan juga berguna untuk menilai derajat infeksius pada pasien. Makin tinggi derajat kepositifan hasil pemeriksaan sputum makin menular pasien tersebut. Berdasarkan tabel hasil pemeriksaan menggunakan metode westergren dapat diartikan bahwa hubungan antara derajat BTA positif dengan laju endap darah adalah tinggi. Namun karena sebagian besar pasien pernah diobati TB yaitu pasien yang sebelumnya pernah menelan OAT selama 1 bulan atau lebih ( $\geq 28$ dosis) maka hasil pemeriksaan LED menjadi menurun dibandingkan dengan pasien yang belum pernah mendapatkan pengobatan ataupun pasien yang sudah pernah menelan OAT namun kurang dari 1 bulan (< dari 28 dosis) (Umaeriyah et al., 2018).

Hasil pengukuran nilai laju endap darah pada sampel darah penderita tuberkulosis yang ditambahkan antikoagulan EDTA dengan metode wintrobe dapat dilihat pada tabel 2.

Tabel 2. Nilai hasil pemeriksaan LED penderita tuberkulosis dengan metode wintrobe

\begin{tabular}{|c|c|c|c|c|}
\hline No. & Nama & Usia & Hasil Pemeriksaan LED & Derajat BTA \\
\hline 1 & Tn "S” & 22 tahun & $46 \mathrm{~mm} / \mathrm{jam}$ & +1 \\
\hline 2 & Tn "A" & 22 tahun & $29 \mathrm{~mm} / \mathrm{jam}$ & +3 \\
\hline 3 & Ny "W" & 28 tahun & $46 \mathrm{~mm} / \mathrm{jam}$ & +2 \\
\hline 4 & Tn "L" & 60 tahun & $20 \mathrm{~mm} / \mathrm{jam}$ & +1 \\
\hline 5 & Tn "D" & 52 tahun & $47 \mathrm{~mm} / \mathrm{jam}$ & +2 \\
\hline 6 & Ny "L" & 74 tahun & $23 \mathrm{~mm} / \mathrm{jam}$ & +1 \\
\hline 7 & Ny "Z” & 45 tahun & $39 \mathrm{~mm} / \mathrm{jam}$ & +1 \\
\hline 8 & Ny "E" & 43 tahun & $40 \mathrm{jam} / \mathrm{jam}$ & +1 \\
\hline 9 & Ny "D" & 24 tahun & $28 \mathrm{~mm} / \mathrm{jam}$ & +1 \\
\hline 10 & Tn "S" & 41 tahun & $18 \mathrm{~mm} / \mathrm{jam}$ & +2 \\
\hline 11 & Tn "S" & 60 tahun & $22 \mathrm{~mm} / \mathrm{jam}$ & +1 \\
\hline 12 & Tn “Z”' & 32 tahun & $34 \mathrm{~mm} / \mathrm{jam}$ & +2 \\
\hline 13 & Tn "M" & 35 tahun & $26 \mathrm{~mm} / \mathrm{jam}$ & +2 \\
\hline 14 & Ny "U”' & 73 tahun & $32 \mathrm{~mm} / \mathrm{jam}$ & +1 \\
\hline 15 & Ny "H" & 27 tahun & $41 \mathrm{~mm} / \mathrm{jam}$ & +2 \\
\hline 16 & Tn "U” & 60 tahun & $29 \mathrm{~mm} / \mathrm{jam}$ & +1 \\
\hline \multicolumn{3}{|c|}{ Jumlah } & $520 \mathrm{~mm} / \mathrm{jam}$ & \\
\hline \multicolumn{3}{|c|}{ Rerata } & $32,5 \mathrm{~mm} / \mathrm{jam}$ & \\
\hline
\end{tabular}

Pada tabel 4.3 menunjukkan bahwa sebagian besar yaitu 56,25\% orang termasuk dalam kategori positif $1,37,5 \%$ orang kategori positif 2 , dan $6,25 \%$ orang kategori positif 3 . Hal ini dapat disimpulkan bahwa sebagian besar penderita tuberkulosis paru termasuk dalam kategori derajat BTA positif 1 yaitu ditemukan 1099 dalam 100 lapang pandang. Tingkat kepositifan juga berguna untuk menilai derajat infeksius pada pasien. Makin tinggi derajat kepositifan hasil pemeriksaan sputum makin menular pasien tersebut. Berdasarkan tabel hasil pemeriksaan menggunakan metode westergren dapat diartikan bahwa hubungan antara derajat BTA positif dengan laju endap darah adalah tinggi. Namun karena sebagian besar pasien pernah diobati TB yaitu pasien yang sebelumnya pernah menelan OAT selama 1 bulan atau lebih ( $\geq 28$ dosis) maka hasil pemeriksaan LED menjadi menurun dibandingkan dengan pasien yang belum pernah mendapatkan pengobatan ataupun pasien yang sudah pernah menelan OAT namun kurang dari 1 bulan ( $<$ dari 28 dosis) (Umaeriyah et al., 2018).

Sebelum mengetahui metode yang paling baik untuk melakukan pemeriksaan laju endap darah (LED), terlebih dahulu dilakukan perhitungan faktor koreksi data kelompok westergren dan wintrobe menggunakan rumus berikut (Norsiah, 2015): 
$F K=\frac{Y}{X}$

Keterangan :

FK : Faktor koreksi

Y : Rerata westergren

$\mathrm{X}$ : Rerata wintrobe

a. Perhitungan faktor koreksi

Diketahui:

$\mathrm{Y}=38,875$

$\mathrm{X}=32,5$

$F K=\frac{Y}{X}$

$$
\begin{aligned}
& =\frac{38,875}{32,5} \\
& =1,1961
\end{aligned}
$$

Jadi, faktor koreksi yang didapatkan yaitu 1,1961.

Kemudian setelah ditemukan nilai faktor koreksi, hasil pemeriksaan nilai laju endap darah menggunakan metode westergren dan metode wintrobe dikalikan dengan faktor koreksi $(1,1961)$, data sesuai pada tabel 3 dan tabel 4 berikut (Norsiah, 2015).

Tabel 3. Nilai hasil pemeriksaan LED penderita tuberkulosis dengan metode wetergren yang dikalikan dengan

\begin{tabular}{|c|c|c|}
\hline No. & Hasil Pemeriksaan LED & $\begin{array}{c}\text { Hasil pemeriksaan LED } \\
\text { dikalikan FK }(1,1961)\end{array}$ \\
\hline 1 & $43 \mathrm{~mm} / \mathrm{jam}$ & $51,43 \mathrm{~mm} / \mathrm{jam}$ \\
\hline 2 & $22 \mathrm{~mm} / \mathrm{jam}$ & $26,31 \mathrm{~mm} / \mathrm{jam}$ \\
\hline 3 & $48 \mathrm{~mm} / \mathrm{jam}$ & $57,41 \mathrm{~mm} / \mathrm{jam}$ \\
\hline 4 & $12 \mathrm{~mm} / \mathrm{jam}$ & $14,35 \mathrm{~mm} / \mathrm{jam}$ \\
\hline 5 & $115 \mathrm{~mm} / \mathrm{jam}$ & $137,55 \mathrm{~mm} / \mathrm{jam}$ \\
\hline 6 & $22 \mathrm{~mm} / \mathrm{jam}$ & $26,31 \mathrm{~mm} / \mathrm{jam}$ \\
\hline 7 & $18 \mathrm{~mm} / \mathrm{jam}$ & $21,52 \mathrm{~mm} / \mathrm{jam}$ \\
\hline 8 & $42 \mathrm{jam} / \mathrm{jam}$ & $50,23 \mathrm{~mm} / \mathrm{jam}$ \\
\hline 9 & $37 \mathrm{~mm} / \mathrm{jam}$ & $44,25 \mathrm{~mm} / \mathrm{jam}$ \\
\hline 10 & $16 \mathrm{~mm} / \mathrm{jam}$ & $19,13 \mathrm{~mm} / \mathrm{jam}$ \\
\hline 11 & $20 \mathrm{~mm} / \mathrm{jam}$ & $23,92 \mathrm{~mm} / \mathrm{jam}$ \\
\hline 12 & $78 \mathrm{~mm} / \mathrm{jam}$ & $93,29 \mathrm{~mm} / \mathrm{jam}$ \\
\hline 13 & $24 \mathrm{~mm} / \mathrm{jam}$ & $28,70 \mathrm{~mm} / \mathrm{jam}$ \\
\hline 14 & $66 \mathrm{~mm} / \mathrm{jam}$ & $78,94 \mathrm{~mm} / \mathrm{jam}$ \\
\hline 15 & $27 \mathrm{~mm} / \mathrm{jam}$ & $32,29 \mathrm{~mm} / \mathrm{jam}$ \\
\hline 16 & $32 \mathrm{~mm} / \mathrm{jam}$ & $38,27 \mathrm{~mm} / \mathrm{jam}$ \\
\hline Jumlah & $622 \mathrm{~mm} / \mathrm{jam}$ & $743,9 \mathrm{~mm} / \mathrm{jam}$ \\
\hline Rerata & $38,875 \mathrm{~mm} / \mathrm{jam}$ & $46,49 \mathrm{~mm} / \mathrm{jam}$ \\
\hline
\end{tabular}
faktor koreksi.

Tabel 4. Nilai hasil pemeriksaan LED penderita tuberkulosis dengan metode wintrobe yang dikalikan dengan faktor koreksi.

\begin{tabular}{|c|c|c|}
\hline No. & Hasil Pemeriksaan & $\begin{array}{c}\text { Hasil pemeriksaan LED } \\
\text { dikalikan FK }(1,1961)\end{array}$ \\
\hline 1 & $46 \mathrm{~mm} / \mathrm{jam}$ & $55,02 \mathrm{~mm} / \mathrm{jam}$ \\
\hline 2 & $29 \mathrm{~mm} / \mathrm{jam}$ & $34,68 \mathrm{~mm} / \mathrm{jam}$ \\
\hline 3 & $46 \mathrm{~mm} / \mathrm{jam}$ & $55,02 \mathrm{~mm} / \mathrm{jam}$ \\
\hline 4 & $20 \mathrm{~mm} / \mathrm{jam}$ & $23,92 \mathrm{~mm} / \mathrm{jam}$ \\
\hline 5 & $47 \mathrm{~mm} / \mathrm{jam}$ & $56,21 \mathrm{~mm} / \mathrm{jam}$ \\
\hline 6 & $23 \mathrm{~mm} / \mathrm{jam}$ & $27,51 \mathrm{~mm} / \mathrm{jam}$ \\
\hline
\end{tabular}




\begin{tabular}{|c|c|c|}
\hline 7 & $39 \mathrm{~mm} /$ jam & $46,64 \mathrm{~mm} / \mathrm{jam}$ \\
\hline 8 & $40 \mathrm{jam} / \mathrm{jam}$ & $47,84 \mathrm{~mm} / \mathrm{jam}$ \\
\hline 9 & $28 \mathrm{~mm} / \mathrm{jam}$ & $33,49 \mathrm{~mm} / \mathrm{jam}$ \\
\hline 10 & $18 \mathrm{~mm} / \mathrm{jam}$ & $21,52 \mathrm{~mm} / \mathrm{jam}$ \\
\hline 11 & $22 \mathrm{~mm} / \mathrm{jam}$ & $26,31 \mathrm{~mm} / \mathrm{jam}$ \\
\hline 12 & $34 \mathrm{~mm} / \mathrm{jam}$ & $40,66 \mathrm{~mm} / \mathrm{jam}$ \\
\hline 13 & $26 \mathrm{~mm} / \mathrm{jam}$ & $31,09 \mathrm{~mm} / \mathrm{jam}$ \\
\hline 14 & $32 \mathrm{~mm} / \mathrm{jam}$ & $38,27 \mathrm{~mm} / \mathrm{jam}$ \\
\hline 15 & $41 \mathrm{~mm} / \mathrm{jam}$ & $49,04 \mathrm{~mm} / \mathrm{jam}$ \\
\hline 16 & $29 \mathrm{~mm} / \mathrm{jam}$ & $34,68 \mathrm{~mm} / \mathrm{jam}$ \\
\hline Jumlah & $520 \mathrm{~mm} / \mathrm{jam}$ & $621,9 \mathrm{~mm} / \mathrm{jam}$ \\
\hline Rerata & $32,5 \mathrm{~mm} / \mathrm{jam}$ & $38,86 \mathrm{~mm} / \mathrm{jam}$ \\
\hline
\end{tabular}

Berdasarkan perhitungan faktor koreksi, didapatkan hasil faktor koreksi 1,1961. Dari tabel terlampir pemeriksaan LED yang dilakukan dengan metode westergren mendapatkan nilai rata-rata hasil LED 38,875 $\mathrm{mm} /$ jam dan memiliki rentang nilai hasil LED 12-115 mm/jam. Berdasarkan tabel terlampir pemeriksaan LED yang dilakukan dengan metode wintrobe mendapatkan nilai rata-rata hasil LED 32,5 $\mathrm{mm} / \mathrm{jam}$ dan memiliki rentang nilai hasil LED 18-47 mm/jam. Tabel 3 hasil pemeriksaan nilai laju endap darah metode westergren setelah dikalikan faktor koreksi $(1,1961)$ diperoleh hasil yang dimana 15 hasil perkalian berada di dalam rentang nilai westergren $(93,75 \%)$. Tabel 4 hasil pemeriksaan nilai laju endap darah metode wintrobe setelah dikalikan faktor koreksi $(1,1961)$ diperoleh hasil yang dimana 11 hasil perkalian berada di dalam rentang nilai wintrobe $(68,75 \%)$. Hasil perkalian metode westergren lebih banyak berada di dalam rentang nilai dari pada hasil perkalian dari metode wintrobe, maka metode westergren adalah metode yang lebih baik untuk melakukan pemeriksaan laju endap darah (LED) (Norsiah, 2015).

Tabel 5. Hasil Analisis Data Mann Whitney

\begin{tabular}{|ll|c|c|c|}
\hline & $\begin{array}{c}\text { Metode } \\
\text { Pemeriksaan LED }\end{array}$ & N & Mean Rank & $\begin{array}{c}\text { Asymp. Sig. } \\
\text { (2-tailed) }\end{array}$ \\
\hline Laju Endap Darah (mm/jam) & Westergreen & 16 & 16.28 & \\
& Wintrobe & 16 & 16.72 & \\
& Total & 32 & & \\
& Laju Endap & & & .895 \\
Asymp. Sig. (2-tailed) & Darah (mm/jam) & & & \\
& & & \\
& & &
\end{tabular}

Berdasarkan uji statistik dengan bantuan SPSS, karena uji normalitas dan homogenitas tidak berdistribusi normal dan tidak homogen, maka dilanjutkan dengan uji statistik Mann Whitney. Berdasarkan tabel uji statistik Mann Whitney yang menunjukkan rata-rata pada setiap kelompok, kelompok westergren reratanya 16,28 dan kelompok wintrobe reratanya 16,72. Dari rerata uji statistik Mann Whitney dapat dilihat metode yang paling baik untuk pemeriksaan LED yaitu kelompok dengan rerata yang lebih kecil yaitu kelompok westergren. Dengan begitu metode westergren adalah metode yang baik untuk pemeriksaan LED sesuai dengan penelitian yang sudah ada. Dari tabel hasil analisis Mann Whitney menunjukkan nilai p 0,895 lebih besar dari $\alpha 0,05$. Karena nilai $\mathrm{p}$ lebih besar dari $\alpha 0,05$ maka dapat disimpulkan bahwa tidak terdapat perbedaan yang bermakna antara dua kelompok dengan begitu Ha ditolak.

\section{Kesimpulan}

Rerata hasil pemeriksaan laju endap darah pada penderita tuberkulosis menggunakan metode westergren yaitu $38,875 \mathrm{~mm} / \mathrm{jam}$. Rerata hasil pemeriksaan laju endap darah pada penderita tuberkulosis menggunakan metode wintrobe yaitu 32,5 mm/jam. Faktor koreksi yang didapatkan yaitu 1,1961 kemudian hasil pemeriksaan masing-masing metode dikalikan dengan faktor koreksi. Hasil analisis Mann Whitney menunjukkan nilai p 0,895 lebih besar dari $\alpha$ 0,05. Karena nilai p lebih besar dari $\alpha 0,05$ maka dapat disimpulkan bahwa tidak terdapat perbedaan yang bermakna antara dua kelompok dengan begitu Ha ditolak. 


\section{Daftar Pustaka}

Cha, C., Park, C., Cha, Y., Kim, H., Kim, D., \& Honghoon. (2009). Erythrocyte Sedimentation Rate Measurements by TEST 1 Better Reflect Inflammation Than Do Those by Westergren Method in Patients with Malignancy, Autoimmune Disease, or Infection. American Journal of Clinical Pathology, 131(1), 94-189.

Dekayana, A. (2019). Hitung Laju Endap Darah (LED) (S. Carsel (ed.); 1st ed.). Uwais Inspirasi Indonesia.

Global Tuberculosis Report. (2017). ISBN 978-92-4-156551-6 @ World Health Organization 2017 Some rights reserved. This work is available under the Creative Commons Attribution-NonCommercial-ShareAlike 3.0 IGO licence (CC BY-NC-SA 3.0 IGO.

Jiwantoro, Y. A., \& Jannah, M. (2019). Pengaruh Ekstrak Pegagan (Centella Asiatica (L.) Terhadap Profil Darah Dan Hepar Pada Tikus Putih Yang Diinduksi Asap Rokok. Jurnal Kesehatan Andalas, 2(1), 99.

Liswanti, Y. (2014). Gambaran Laju Endap Darah (Metode Sedimat) Menggunakan Natrium Sitrat 3,8\% dan EDTA yang Ditambah $\mathrm{NaCl}$ 0,85\%. Jurnal Kesehatan Bakti Tunas Husada, 12(1).

Norsiah, W. (2015). Perbedaan Kadar Hemoglobin Metode Sianmethemoglobin Dengan dan Tanpa Sentrifugasi pada Sampel Leukositosis. Medical Laboratory Technology Journal, 1(2), 72-83.

Umaeriyah, Santosa, B., \& Sukeksi, A. (2018). Hubungan Derajat BTA Positif dengan Laju Endap Darah pada Penderita Tuberculosis Paru. Universitas Muhammadiyah Semarang. 